\title{
OPEN Potential local adaptation of corals at acidified and warmed Nikko Bay, Palau
}

\author{
Haruko Kurihara ${ }^{1 凶}$, Atsushi Watanabe ${ }^{2,3}$, Asami Tsugi ${ }^{1}$, Izumi Mimura ${ }^{1}$, Chuki Hongo ${ }^{1}$, \\ Takashi Kawai ${ }^{1}$, James Davis Reimer ${ }^{1}$, Katsunori Kimoto ${ }^{4}$, Marine Gouezo ${ }^{5}$ \& \\ Yimnang Golbuu ${ }^{5}$
}

Ocean warming and acidification caused by increases of atmospheric carbon dioxide are now thought to be major threats to coral reefs on a global scale. Here we evaluated the environmental conditions and benthic community structures in semi-closed Nikko Bay at the inner reef area in Palau, which has high $p \mathrm{CO}_{2}$ and seawater temperature conditions with high zooxanthellate coral coverage. Nikko Bay is a highly sheltered system with organisms showing low connectivity with surrounding environments, making this bay a unique site for evaluating adaptation and acclimatization responses of organisms to warmed and acidified environments. Seawater $p \mathrm{CO}_{2} / \Omega_{\text {arag }}$ showed strong gradation ranging from 380 to $982 \mu \mathrm{atm}\left(\Omega_{\text {arag }}: 1.79-3.66\right)$, and benthic coverage, including soft corals and turf algae, changed along with $\Omega_{\text {arag }}$ while hard coral coverage did not change. In contrast to previous studies, net calcification was maintained in Nikko Bay even under very low mean $\Omega_{\text {arag }}$ (2.44). Reciprocal transplantation of the dominant coral Porites cylindrica showed that the calcification rate of corals from Nikko Bay did not change when transplanted to a reference site, while calcification of reference site corals decreased when transplanted to Nikko Bay. Corals transplanted out of their origin sites also showed the highest interactive respiration $(\mathrm{R})$ and lower gross photosynthesis $(\mathrm{Pg})$ to respiration (Pg:R), indicating higher energy acquirement of corals at their origin site. The results of this study give important insights about the potential local acclimatization and adaptation capacity of corals to different environmental conditions including $p \mathrm{CO}_{2}$ and temperature.

Increases in atmospheric carbon dioxide $\left(\mathrm{CO}_{2}\right)$ simultaneously cause both ocean warming and acidification, which are now thought to be the major threats to coral reefs on a global scale ${ }^{1,2}$. Coral mass bleaching events are now occurring more frequently compared to the past, and ocean warming is predicted to further increase the susceptibility of corals to bleaching in the coming decades ${ }^{3,4}$. Some studies have indicated that zooxanthellate corals may have the ability to adapt to high temperature environments, such as by shuffling to Symbiodiniaceae types that have higher tolerances to warmer temperature ${ }^{5-7}$. In addition to global warming, increases of seawater partial pressure of $\mathrm{CO}_{2}\left(p \mathrm{CO}_{2}\right)$ and decreases of aragonite calcium carbonate saturation $\left(\Omega_{\text {arag }}\right)$ have been reported to decrease calcification rates of most reef calcifiers including corals and crustose coralline algae $(\mathrm{CCA})^{8,9}$. Meanwhile, it has been shown that the tolerance of organisms to high $p \mathrm{CO}_{2}$ can differ among species and even within species ${ }^{10}$. Hence, there is now wide interest in understanding how reef organisms will respond to ocean warming and acidification at the community level, and to examine if organisms are able to acclimatize or adapt to these environmental changes.

Here we investigated a semi-closed bay (Nikko Bay) in the inner reef area in Palau (Fig. 1) with high $p \mathrm{CO}_{2}$ and high-temperature conditions, and counter-intuitively, high coral coverage ${ }^{11,12}$. The elevated $p \mathrm{CO}_{2}$ observed in this bay has been suggested to be mainly due to natural biological activity and seawater circulation ${ }^{12,13}$. Nikko Bay's corals have shown little evidence of bleaching during the 1998 mass bleaching on other reefs of Palau and during the 2010 thermal stress event ${ }^{11,14}$. A global mass bleaching event occurred in $2016-2017^{3}$, however, it

\footnotetext{
${ }^{1}$ Department of Chemistry, Biology, and Marine Science, Faculty of Science, University of the Ryukyus, 1 Senbaru, Nishihara, Okinawa 903-0213, Japan. ${ }^{2}$ Department of Transdisciplinary Science and Engineering, School of Environment and Society, Tokyo Institute of Technology, 2-12-1 W8-13, Meguro, Tokyo 152-8550, Japan. ${ }^{3}$ The Ocean Policy Research Institute, The Sasakawa Peace Foundation, 1-15-16 Toranomon, Minato, Tokyo 105-8524, Japan. ${ }^{4}$ Research Institute for Global Change, Japan Agency for Marine-Earth Science and Technology (JAMSTEC), 2-15, Natsushima-cho, Yokosuka, Kanagawa 237-0061, Japan. ${ }^{5}$ Palau International Coral Reef Center, 1 M-Dock Road, PO Box 7086, Koror 96940, Republic of Palau. ${ }^{\square}$ email: harukoku@sci.u-ryukyu.ac.jp
} 

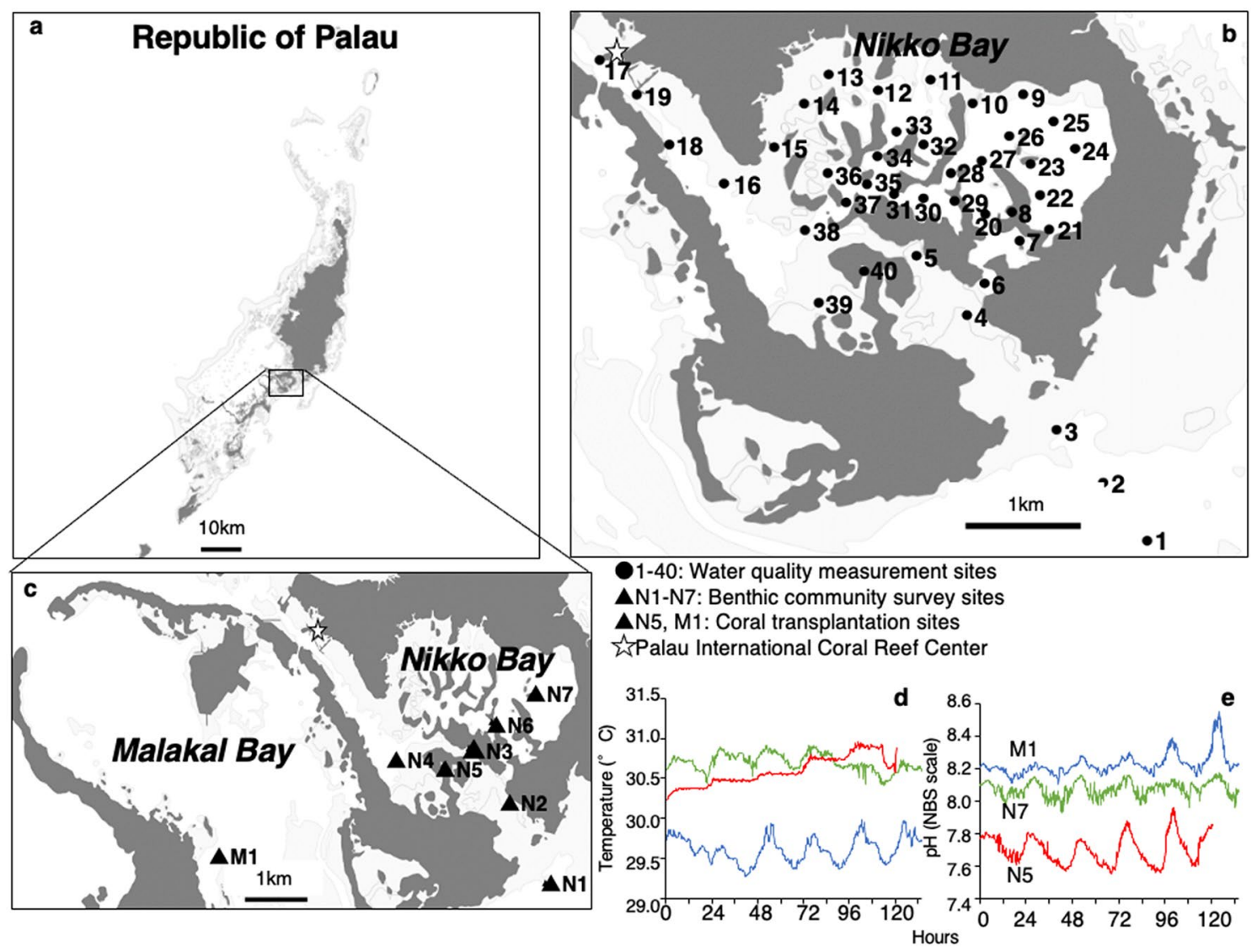

Figure 1. Map showing study sites and seawater temperature and $\mathrm{pH}$ at 3 sites (M1, N7, N5). (a) Map of the Republic of Palau. (b) The 40 locations where seawater quality was measured around Nikko Bay. (c) The seven sites (N1-N7) where benthic communities were surveyed and the reference site at Malakal Bay (M1) where the coral Porites cylindrica experiment was conducted. The coral P. cylindrica was sampled from sites M1 and N5 for reciprocal transplantation experiment. (d) Diurnal seawater temperature and (e) pH (total scale) measured at Malakal Bay (M1) and two sites at Nikko Bay (N7 and N5). The figure was created using QGIS 3.8.1 (https:// www.qgis.org).

only affected eastern parts of Micronesia ${ }^{15}$. Palau's SST rapidly shifted in March 2016 and reached above $30{ }^{\circ} \mathrm{C}$ in June 2016 but quickly decreased afterward and bleached corals quickly recovered instead of dying ${ }^{16}$, leading to no decrease in percentage of live coral cover at the scale of the archipelago ${ }^{17}$.

$\mathrm{CO}_{2}$ vent sites ${ }^{18-20}$ and naturally acidified sites ${ }^{21-23}$ have been found on coral reefs and utilized as essential models for evaluating the effects of ocean acidification at the ecosystem level. However, most of these systems are open or semi-closed lagoon ecosystems with significantly shorter residence times compared with that of Nikko Bay, and thus they may continuously receive recruitment from the surrounding ocean; this may limit local adaptation of organisms to high $p \mathrm{CO}_{2}$ conditions. On the other hand, Nikko Bay is of particular interest because it is a highly sheltered system with a long seawater residence time of 71 days, and with organisms showing low connectivity with surrounding populations ${ }^{12,24}$. Additionally, the seawater conditions found in this bay have been suggested to have been maintained at least for the past 150-500 years ${ }^{12}$ and hence, long-term selection of coral larvae may have allowed local adaptation or acclimatization responses to environmental conditions found within this bay. Finally, this unique bay provides opportunities to evaluate the effects of the co-stressors of ocean warming, ocean acidification, low oxygen and high chlorophyll- $a$ (Chl- $a$ ) levels, at the community scale. Recent studies in mangrove habitats ${ }^{22,25}$, tidal inshore reefs ${ }^{26}$, and upwelling systems ${ }^{27}$ have demonstrated the need and importance of evaluating these multiple co-varying factors in understanding the mechanisms sustaining complex ecosystems and in predicting future coral reef $\operatorname{scenarios}^{28}$.

Here we evaluated the environmental conditions and benthic community structures along with the $\Omega_{\text {arag }}$ gradient found within the bay. We also conducted reciprocal transplantation experiments of the most dominant coral species, Porites cylindrica, to evaluate the potential acclimatization and adaptive responses of corals to warm and acidified conditions.

\section{Results and discussion}

Seawater surface $\mathrm{pH}$ (total scale), $\Omega_{\mathrm{arag}}$ and temperatures (SST) showed a strong gradient at the entrance into the bay (Fig. 2a, b, e) and the seawater $\mathrm{pH}$ range (7.65-8.02) observed within the bay was equivalent to the ocean $\mathrm{pH}$ value from present to the value expected by the end of this century (IPCC 2013, RCP 8.5) ${ }^{29}$. The mean daytime 

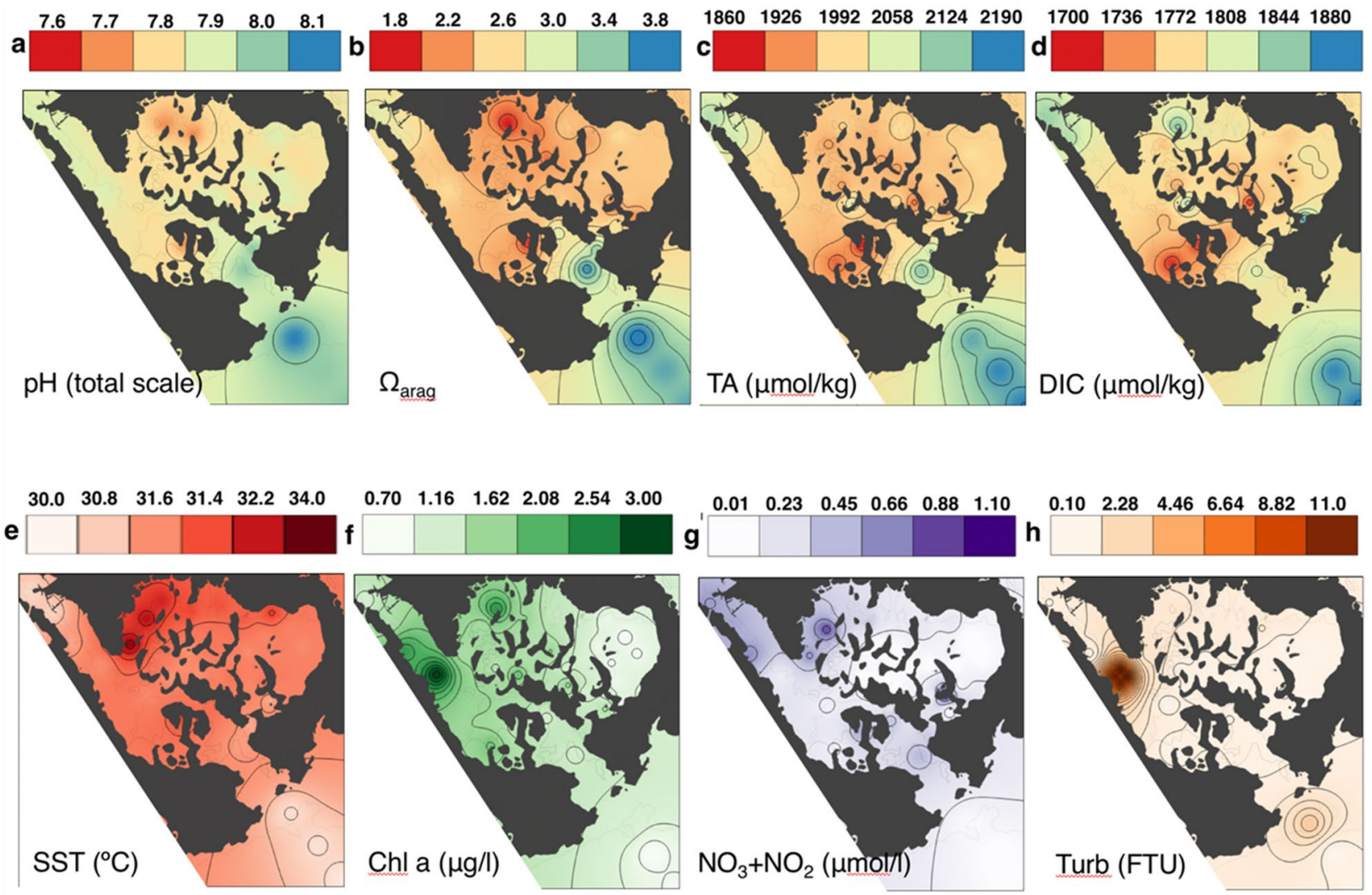

Figure 2. Spatial gradient of (a) $\mathrm{pH}$ (total scale), (b) aragonite saturation state $\left(\Omega_{\mathrm{arag}}\right)$, (c) total alkalinity (TA, $\mu$ mol equivalent $\mathrm{kg}^{-1}$ ), (d) dissolved inorganic carbon (DIC, $\mu \mathrm{mol} \mathrm{kg}^{-1}$ ), (e) sea surface temperature (SST, ${ }^{\circ} \mathrm{C}$ ), (f) chlorophyll- $a$ (Chl- $a$, $\left.\mu \mathrm{g} \mathrm{L}^{-1}\right)$, (g) nitrate + nitrite $\left(\mathrm{NO}_{2}{ }^{-}+\mathrm{NO}_{3}^{-}, \mu \mathrm{mol} \mathrm{L}{ }^{-1}\right)$ and (e) turbidity (FTU) in sea surface water during daytime around Nikko Bay. See Tables S1 and S2 for details. The figure is created using QGIS 3.8.1 (https://www.qgis.org).

seawater temperature within the bay was significantly warmer $\left(31.8 \pm 0.6^{\circ} \mathrm{C}\right.$, mean \pm S.D. $)$ and had lower $\mathrm{pH}$ $(7.83 \pm 0.06)$, lower $\Omega_{\mathrm{arag}},(2.44 \pm 0.34)$ and higher $\mathrm{pCO}_{2}(619 \pm 104 \mu \mathrm{atm})$ compared to parameters outside the bay $\left(30.4 \pm 0.1{ }^{\circ} \mathrm{C}, 8.02 \pm 0.02,391 \pm 31 \mu \mathrm{atm}, 3.63 \pm 0.14\right.$, Wilcoxon-test, $p<0.01$, Tables S2), respectively. The seawater $\mathrm{pH}$ at Nikko Bay showed diurnal variation, ranging from 0.05 to 0.25 , which was consistent with the range observed outside the bay (Fig. 1e, Table S2) and at other coral reefs ${ }^{30}$. This contradicts with most conditions at $\mathrm{CO}_{2}$ vents where the seawater $\mathrm{pH}$ is highly variable temporally ${ }^{18-20}$. Average Chl- $a$ and nutrient concentration values inside Nikko Bay were slightly but significantly higher than those outside the bay (Wilcoxon-test, $p<0.01$, Fig. 2f-g, Table S1).

Daytime average total alkalinity (TA) and dissolved inorganic carbon (DIC) were significantly lower within the bay compared to outside the bay (Wilcoxon-test, $p<0.01$, Fig. $2 c$, d, Table S2) and the TA-DIC diagram indicated that the low $\mathrm{pH}$ and high $p \mathrm{CO}_{2}$ within Nikko Bay were mainly caused by low seawater TA due to calcification and by high DIC due to respiration (Fig. 3). By using the calculated mean water residence time within the bay $\left(71\right.$ days $\left.^{12}\right)$, mean net calcification $(\mathrm{Gn})$ and net primary production $(\mathrm{Pn})$ rates within the bay were calculated to be $22.7 \mathrm{mmol} \mathrm{CaCO}_{3} \mathrm{~m}^{-2} \mathrm{~d}^{-1}$ and $-6.9 \mathrm{mmol} \mathrm{C} \mathrm{m}^{-2} \mathrm{~d}^{-1}$. These values were lower than the net calcification rates found at most reefs ${ }^{31}$, however the positive net calcification at seawater $\Omega_{\text {arag }}$ of 2.44 within the bay contradicts with previous studies suggesting that coral reef formation is restricted to seawater $\Omega_{\text {arag }}$ higher than ca. $2.8\left(p \mathrm{CO}_{2}\right.$ lower than $560 \mu \mathrm{atm})^{32}$, and also with $\mathrm{CO}_{2}$ seep studies indicating that reef development ceases where $\mathrm{pH}$ is lower than $7.7\left(\Omega_{\text {arag }} 2.1\right)$ in Papua New Guinea ${ }^{18}$, and lower than 7.9 in the Mariana Islands ${ }^{20}$. When $\mathrm{CO}_{2}$ gas exchange is considered, the heterotrophy of Nikko Bay becomes even higher. Although there are no wind speed data measured directly inside Nikko Bay, wind speed measured at PICRC station was $0.51 \pm 0.80 \mathrm{~m} \mathrm{~s}^{-1}(\mathrm{~N}=4320)$ during this period, and wind can be expected to be weaker in Nikko Bay, which is surrounded by islands. Using the average $p \mathrm{CO}_{2}$ of seawater in the bay $\left(670 \mu \mathrm{atm}\right.$, Table S2), atmospheric $\mathrm{pCO}_{2}(390 \mu \mathrm{atm}$, calculated from mole fraction of $\mathrm{CO}_{2}$ in dry air data collected at Guam), and gas exchange coefficient ${ }^{33}$ utilized; gives the largest gas flux under this condition), the $p \mathrm{CO}_{2}$ flux was calculated to be about $5.6 \mathrm{mmol} \mathrm{m}^{-2} \mathrm{~d}^{-1}$. Using this value, the Pn in Nikko Bay would be approximately $-12.5 \mathrm{mmol} \mathrm{m}^{-2} \mathrm{~d}^{-1}$.

To evaluate the correlation among seawater carbonate chemistry and benthic community structure, six sites (N2-N7) along with the $\Omega_{\text {arag }}$ gradient (1.28-3.51) inside the bay and one site outside of Nikko Bay (N1) were selected for benthic community observation (Fig. 1, Table S3). Even though the seawater inside the bay was warmer and more acidified than the seawater outside the bay, hard coral coverage inside the bay (N2-N7) ranged 


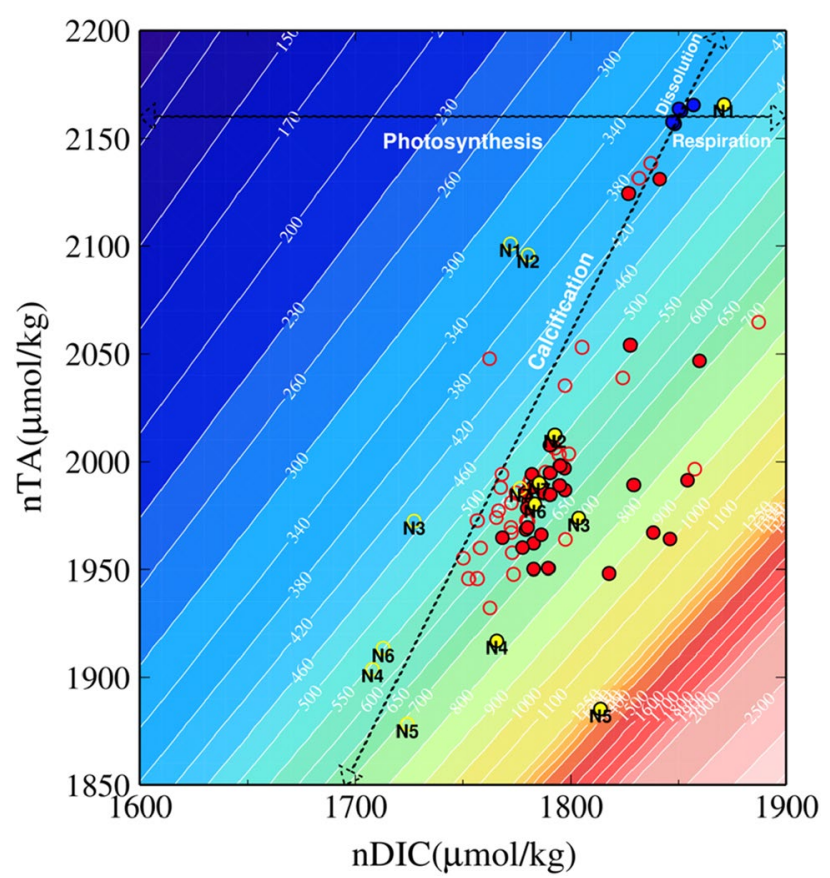

Figure 3. Salinity normalized TA-DIC diagram for the seawater collected around Nikko Bay. Data are normalized at the mean Nikko Bay salinity of 33.02 during the survey. Yellow symbols indicate data collected from N1 to N7 (Fig. 1c) during daytime (open) and at nighttime (filled). Red symbols indicate samples collected at other sites in Nikko Bay during daytime (open) and at nighttime (filled). Blue symbols indicate data collected at far offshore sites as end members. Trend lines indicating calcification, dissolution, photosynthesis, and respiration are drawn from these offshore end member values. Contours indicate $p \mathrm{CO}_{2}$ isolines calculated at $\mathrm{S}=33.02$ and $\mathrm{T}=30^{\circ} \mathrm{C}$.

from 34 to $82 \%$, while the coverage at the N1 site outside the bay was $24 \%$ (Tables S4). There was no significant correlation between seawater $\Omega_{\mathrm{arag}}$ and scleractinian hard coral cover (GLM, $p=0.97$ ), CCA (GLM, $p=0.68$ ), macroalgae, or seagrass coverage (GLM, $p=0.06$, Fig. S1, Table S5). On the other hand, there was a significant increase in soft coral (=octocoral) coverage with an observed decrease of $\Omega_{\text {arag }}$ (GLM, $p=0.01$ ), which follows previous results at a $\mathrm{CO}_{2}$ vent at Iwotorishima in southern Japan showing high coverage of soft coral at a high $p \mathrm{CO}_{2}$ site $^{19}$. Turf algae coverage increased with $\Omega_{\text {arag }}(\mathrm{GLM}, p=0.04)$, contradicting previous observations at a $\mathrm{CO}_{2}$ vent in the Mariana Islands ${ }^{20}$ (Table S5, Fig. S1). In Nikko Bay, the coral community was found to differentiate along with the $\Omega_{\text {arag }}$ gradient observed from the outer reef to the inner reef area ${ }^{23}$. Here we found that although coral coverage was not affected, the hard coral community structure showed differentiation among sites within the inner reef bay area, and this structure was mainly predicted by seawater $\Omega_{\text {arag}}$, dissolved oxygen (DO), Chl$a$, nitrate plus nitrite $\left(\mathrm{NO}_{3}{ }^{-}+\mathrm{NO}_{2}{ }^{-}\right)$concentration, $p \mathrm{CO}_{2}$ and temperature (Fig. 4, Table S6). Site $\mathrm{N} 1$ (outside of the bay) was characterized by high $\Omega_{\mathrm{arag}}(3.51)$, low $p \mathrm{CO}_{2}(395 \mu \mathrm{atm})$, low temperature $\left(29.3^{\circ} \mathrm{C}\right)$, low Chl- $a$ $(0.55 \mu \mathrm{g} / \mathrm{L})$, high DO $(6.09 \mathrm{mg} / \mathrm{L})$, and was dominated by Acropora spp. (coverage $16.5 \pm 4.1 \%)$, while site N5 was characterized by low $\Omega_{\text {arag }}(1.28)$, high $p \mathrm{CO}_{2}(1,305 \mu \mathrm{atm})$, high temperature $\left(30.5^{\circ} \mathrm{C}\right)$, high Chl- $a(1.68 \mu \mathrm{g} / \mathrm{L})$, low DO (4.52 mg/L), and was dominated by Merulinidae spp. (15.6 $\pm 5.2 \%$, Fig. 4, Tables S3-S5). Both Acropora spp. and massive Porites showed a slight but positive correlation with seawater $\Omega_{\text {arag }}$ (GLM, $p=0.04$, Fig. S1, Table S5), suggesting that species belonging to these genera are sensitive to OA, though other environmental factors may also have interactively affected the coverage of those species. Branching Porites (mainly consisting of Porites cylindrica) showed the highest coverage, accounting for 22 to $79 \%$ of hard coral cover inside the bay (Fig. 4g, Table S4), and there was no significant correlation with branching Porites spp. and $\Omega_{\text {arag }}$ (GLM, $p=0.16$, Table S5. These results suggest that the high coral cover observed within Nikko Bay is related to the potential acclimatization or adaptation capacity of corals such as $P$. cylindrica to high $p \mathrm{CO}_{2}$ (low $\Omega_{\text {arag }}$ ) seawater.

To determine this possibility, colonies of $P$. cylindrica were reciprocally transplanted between two inner reef bays; a reference site at Malakal Bay (site M1) and a site in Nikko Bay (site N5, Fig. 1) that had different seawater temperatures and $p \mathrm{CO}_{2}$ conditions (Table S7). As a result, it was found that while the calcification rate of $P$. cylindrica originating from M1 significantly decreased when transplanted to N5, the calcification rate of corals from N5 did not show significant differences when transplanted to either M1 and N5 (Fig. 5a, Table S8). Most previous tank experiments have reported a decrease of calcification rates of $P$. cylindrica at high $p \mathrm{CO}_{2}{ }^{34,35}$ or under high $\mathrm{pCO}_{2}$ and high temperature conditions ${ }^{36}$. Additionally, in contrast to massive Porites, $P$. cylindrica was found to have less capacity of up-regulating calicoblastic calcifying fluid $\mathrm{pH}$, suggesting a high sensitivity to increases of seawater $p \mathrm{CO}_{2}{ }^{37}$. Additionally, the skeleton density of $P$. cylindrica did not show significant differences among sites (Fig. S2), again contradicting previous studies that showed lower skeleton densities of corals 

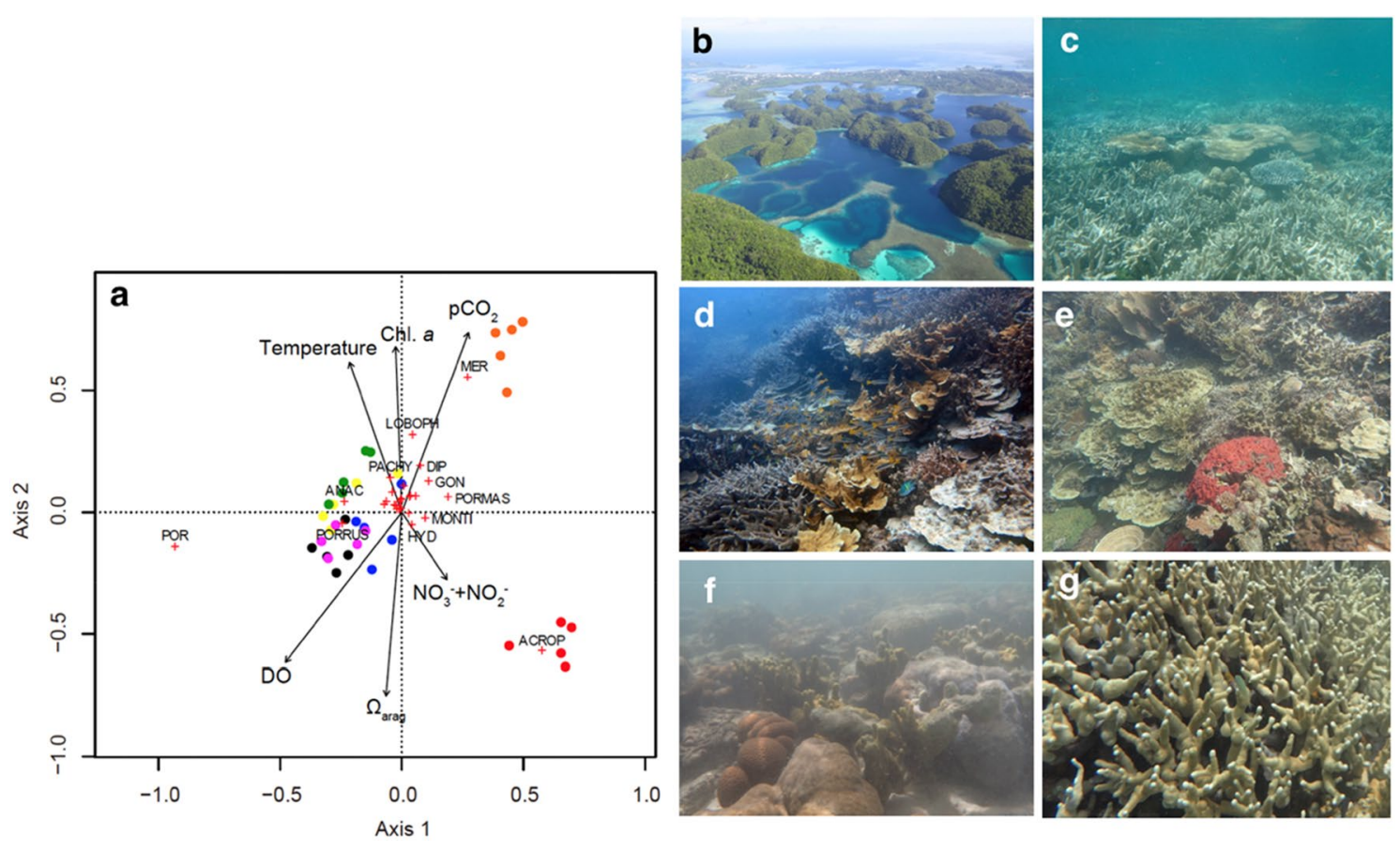

Figure 4. Redundancy analysis (RDA) for water quality and hard coral community at seven sites around Nikko Bay (N1-N7) and image of sites with different benthic communities. (a) Ordination of coral community based on redundancy analysis (Eigenvalue axis 1: 0.1795, Eigenvalue axis 2: 0.1035). Arrows represent significant seawater environmental variables, and their direction and length indicate their contributions to variation along those axes. Dots indicate transect lines with colors distinguishing study sites: red: N1, black: N2, blue: N3, yellow: N4, light blue: N5, green: N6, pink: N7. Genera/families of hard corals are indicated by plus symbols; selected genera are indicated by codes: LOBOPH: Lobophyllia spp., ACROP: Acropora spp., ANAC: Anacropora spp., MONTI: Montipora spp., MER: Merulinidae, DIP: Dipsastrea spp., GON: Goniastrea spp., HYD: Hydnophora spp., PACHY: Pachyseris spp., POR: branching Porites spp., PORMAS: massive Porites spp., PORRUS: Porites rus. (b) aerial image of Nikko Bay, $(\mathbf{c})$ image of site N1 $\left(\Omega_{\mathrm{arag}}=3.51\right)$, a reef outside of Nikko Bay mainly covered by Acropora spp., (d) image of site N6 $\left(\Omega_{\text {arag }}=2.41\right)$ within Nikko Bay mainly covered by Porites spp., Pachyseris spp. and Anacropora spp., (e) image of site N7 $\left(\Omega_{\text {arag }}=2.36\right)(\mathbf{f})$ image of site N5 $\left(\Omega_{\mathrm{arag}}=1.28\right)$ mainly covered by Merulinidae and Porites spp, and (g) image of the most dominant coral Porites cylindrica.

at a $\mathrm{CO}_{2}$ vent $^{38}$ and naturally acidified sites ${ }^{39}$. The net photosynthesis (Pn) rate of $P$. cylindrica transplanted to site N5 had a significantly higher value $(p=0.04)$ regardless of their origin (Fig. 5b, Table S8), which may be related to the slightly higher nutrient concentrations at N5 site (Table S7). Respiration (R) rates showed interactive effects among transplanted site and origin site, and the R rate of both M1 and N5 corals was significantly lower when transplanted to their origin site (Fig. 5c, Table S8). As a result, there were also interactive effects among the transplanted site and origin site with regards to gross photosynthesis $(\mathrm{Pg}): \mathrm{R}$, with higher values when transplanted to their original site (Fig. 5d, Table S8), indicating higher energy acquirement of corals at their own origin site. Interestingly, the corals Acropora pulchra, Porites lutea and Coelastrea aspera in a semi-enclosed lagoon of New Caledonia with low $\mathrm{pH}$, high temperature, low oxygen conditions but high coral coverage, were found to exhibit lower calcification, higher respiration (R) and lower Pg:R compared to corals outside of the lagoon ${ }^{25}$. Acclimatization of corals at the New Caledonia lagoon was suggested to be caused by high respiration through potentially high heterotrophy of corals within the lagoon, which has high organic carbon sedimentation ${ }^{25}$. A comparatively high heterotrophy of the corals in Nikko Bay is also suggested as zooplankton abundance (particularly copepod abundance) was observed to be higher at site N5 compared to reference site M1 (Fig. 6), and this may partially alleviate the effects of high temperature and high $\mathrm{CO}_{2}$ by enhancing their energy availability ${ }^{40,41}$. However, taking into account that only the calcification rate of $P$. cylindrica at site M1 decreased when transplanted to site $\mathrm{N} 5$, potential epigenetic or genetic adaptation to the environmental conditions found within the bay appears to have occurred for Nikko Bay corals. This is also indicated by other findings that showed Pocillopora acuta within Nikko Bay had higher calcification rates when transplanted to their original site than out of the bay, while $P$. acuta from out of the bay were not able to survive when transplanted within the bay ${ }^{42}$.

P. cylindrica from N5 was also found to host two types of Cladocopium subclade $\mathrm{C}^{43}$ (former Symbiodinium 'Clade C'), as well as Durusdinium ${ }^{43}$ (former Symbiodinium 'Clade D'), which are known to be tolerant to high temperatures ${ }^{44}$, while P. cylindrica from the other sites only hosted Cladocopium subclade C1 (Fig. S3). These differences in Symbiodiniaceae, particularly at the most sheltered Nikko Bay site, may be another adaptation mechanism of corals to the environment found within Nikko Bay. However, molecular studies evaluating the potential genetic differentiation of those host corals within the bay are first needed before implying the occurrence of local 

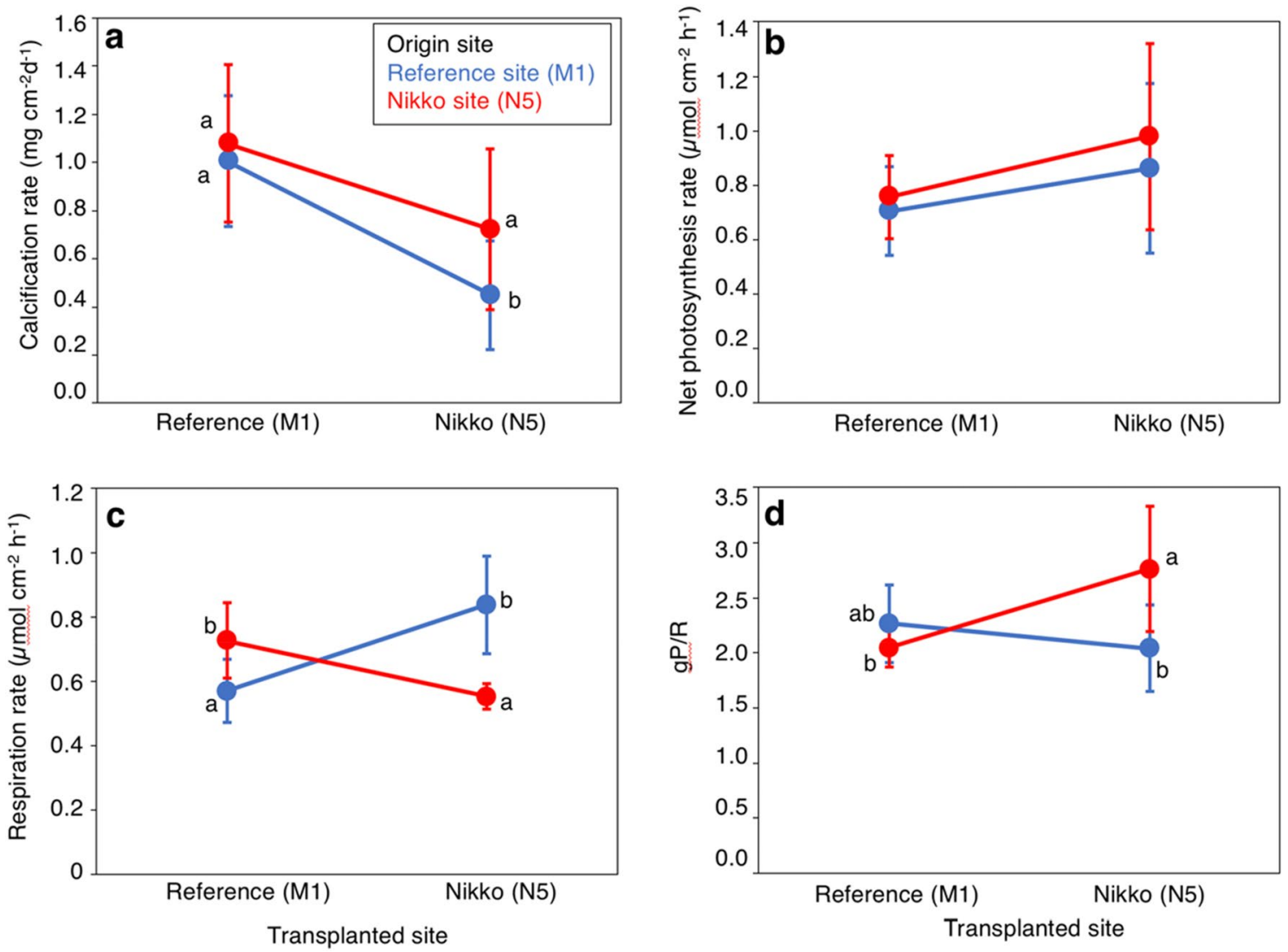

Figure 5. Metabolism of the coral Porites cylindrica reciprocally transplanted between the reference site (M1) and Nikko Bay site (N5). (a) Calcification rate $(\mathrm{n}=12)$, (b) net photosynthesis rate $(\mathrm{Pn}, \mathrm{n}=9)$, (c) respiration rate $(\mathrm{R}, \mathrm{n}=9)$, and $(\mathbf{d})$ gross photosynthesis ratio to respiration $(\mathrm{Pg}: \mathrm{R}, \mathrm{n}=9)$ of $P$. cylindrica originated from the reference site M1 (blue) and Nikko Bay site N5 (red), and reciprocally transplanted for 18 days to either sites. Bars with different lower letters show significant differences among them (Tukey-Kramer HSD, $p<0.05$ ).

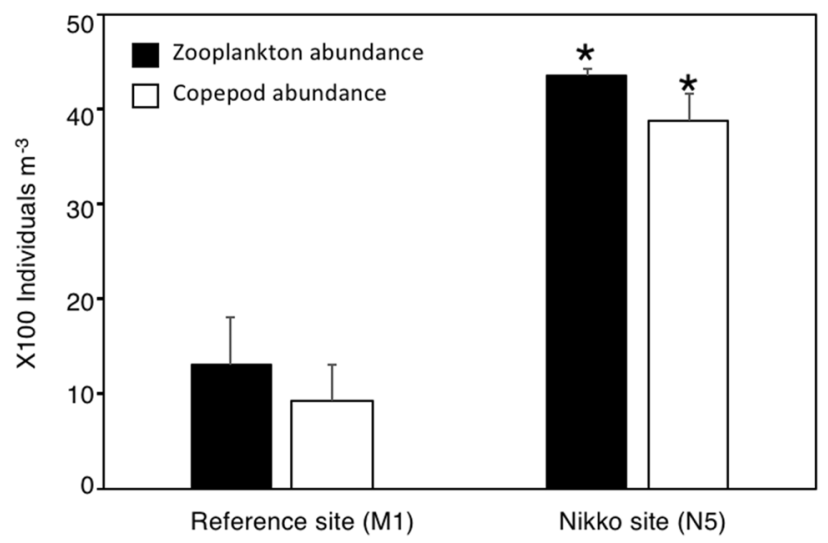

Figure 6. Zooplankton (black bar) and copepod (write bar) abundances at reference site (M1) and Nikko Bay site (N5). Average and S.D. for 3 nights plankton net sampling at each site. Asterisks show significant differences between the two sites (student $t$-test, $p<0.05$ ).

adaptation. Thus, for further understanding, molecular studies evaluating the potential genetic differentiation of these host corals within the bay are essential in evaluating of the possibility of local adaptation.

From the present study, coral community structure was found to change according to the seawater environmental conditions within the bay, and corals living within the bay such as $P$. cylindrica could maintain their fitness in the warmed and acidified conditions found within the bay. However, interpretation of these results as related to future climate change should be taken carefully, as several other environmental factors including Chl- $a$, DO, 
inorganic nutrient concentrations, and light intensities also varied among sites. Additionally, corals within this bay have been suggested to have been continuously exposed to the unique environment within Nikko Bay for at least the past $150-500$ years $^{12}$, while climate change is predicted to continue for the next few decades to centuries. Nevertheless, these results give important insights about the potential acclimatization and adaptation capacities of corals to different environmental conditions, even at small spatial scales, on coral reefs.

\section{Methods}

Water quality measurements. The carbonate chemistry including total alkalinity (TA), dissolved inorganic carbon (DIC), aragonite saturation $\left(\Omega_{\mathrm{arag}}\right)$, and water quality parameters including chlorophyll- $a(\mathrm{Chl}-a)$, turbidity (FTU), dissolved oxygen (DO) and inorganic nutrients (DIN, DIP) were measured once each during daytime and nighttime from 40 sites around Nikko Bay (Supplementary Fig. S1, Tables S1, S2).

Water quality measurements in Nikko Bay were conducted during daytime before sunset (15:00-18:00) and during nighttime around sunrise (5:00-8:00) between 17 to 19 November, 2014 at 40 sites (Fig. 1). Water samples were taken before sunset and after sunrise because of the following assumptions. Net primary production and calcification continue until compensation light intensity reaches near sunset, and therefore DIC and TA reach their minimum values around sunset in a closed system. On the other hand, respiration and dissolution continue until sunrise, so DIC and TA are at their maximum around sunrise in a closed system. Because of the highly closed nature of Nikko Bay, it is safe to assume that the range of diel changes in DIC and TA can be captured by collecting water at two time points, around sunset and around sunrise. As well, the middle value of these two time points can give the average value of the system. Seawater temperature, salinity, depth, Chl- $a$ (fluorescent chloride sensor), dissolved oxygen (DO, phosphoresce based oxygen sensor) and turbidity (FTU, backscattering sensor, formazin reference) were measured by vertical casting (1 s logging interval) using a multi-parameter sensor (AAQ-Rinko, JFE Advantech). Salinity data was calibrated by a salinometer (PORTASAL 8410A, Guildline Instruments), and Chl- $a$ (3 replicates) by a fluorometer (Trilogy, Turner Designs). Surface water samples for TA, DIC (2 replicates) and nutrient (DIN, DIP) measurements (4 replicates) were collected from the same sites. TA and DIC were measured within $24 \mathrm{~h}$ after seawater collection using an auto burette titrator (ATT05, Kimoto Electronic Co. Ltd.), which has an accuracy of $\pm 2 \mu \mathrm{mol} \mathrm{Kg}{ }^{-1}$ for TA and $\pm 3 \mu \mathrm{mol} \mathrm{Kg}^{-1}$ for DIC and standardized by certified reference materials obtained from A. Dickson Laboratory (Scripps Institution of Oceanography, Batch 139). When samples were not measurable within $24 \mathrm{~h}$, they were poisoned with saturated mercury chloride and kept within air-tight glass vial bottles, and these samples were measured within a few days after collection. Nutrient samples were stored in a freezer $\left(-20^{\circ} \mathrm{C}\right)$ until measurement by nutrient autoanalyzer (AACSIII, BRAN + LUEBEE). Carbonate chemistry was calculated from measured TA, DIC and surface salinity and temperature measured at $30 \mathrm{~cm}$ below the seawater surface by a casting sensor using CO2SYS ${ }^{45}$ with the constants of Mehrbach et al. ${ }^{46}$ as refit by Dickson and Millero ${ }^{47}$, and aragonite solubility of Mucci ${ }^{48}$. The accuracy of calculated $p \mathrm{CO}_{2}$ is estimated as approximately $2-3 \%$ of the measurement range of Nikko Bay (see Anderson et $a .^{49}$ for calculation of propagation error).

Mean net calcification and primary production in Nikko Bay were calculated from the differences between the average of inside Nikko Bay TA and DIC ( $n=74$ data each, Table S2) and offshore end-members, the average depth of the bay $(\mathrm{d}=18 \mathrm{~m})$, and the mean water residence time within the bay $\left(\tau=71\right.$ days $\left.{ }^{12}\right)$, by simply assuming these TA and DIC differences were accumulated in the bay during this residence time; mean net calcification rate $(\mathrm{Gn})$ was calculated from the TA differences, $\tau$, $d$, and seawater density $(\rho)$, and primary productivity $(\mathrm{Pn})$ rate was calculated from DIC and TA differences, $\tau, \mathrm{d}$, and $\rho$ (see Kayanne et al. ${ }^{30}$ and Watanabe et al. ${ }^{50}$ ). For the calculation TA and DIC were normalized at $S=33.02$ which was the mean salinity of Nikko Bay.

In addition to seawater multi-station measurements across the entire bay, several measurements were conducted during the subsequent benthic survey and coral transplantation survey. Seawater qualities ( $3 \mathrm{~m}$ depth) for the seven sites where benthic surveys were conducted were measured using the AAQ-Rinko in the same manner as above. Additionally, seawater samples were taken at $3 \mathrm{~m}$ depths using Van Dorn samplers to measure TA, DIC, and nutrients. During coral transplantation, bottom seawater was sampled using Van Dorn samplers on October 17, 2015 for measurement of Chl- $a$ (3 replicates), nutrients (4 replicates), and suspended solids (3 replicates). Seawater carbonate chemistry (TA and DIC) was measured by collecting two replicate water samples three times (17 Oct, 28 Oct and 5 Nov, 2015) during transplantation. pH and temperature loggers (SPS-14, Kimoto Electrode, Japan) were also deployed at the three transplantation sites for ca. 5 days. The $\mathrm{pH}$ data for the loggers were calibrated using TRIS-AMP buffers and are reported in the total scale.

Benthic community survey. Benthic coverage including coral community cover (at the genus level) was determined by taking $0.5 \times 0.5 \mathrm{~m}$ photo-quadrats every meter along five $50 \mathrm{~m}$ transects at $3 \mathrm{~m}$ depth. A total of 50 photographs were taken per transect and per depth at each site; representing an area of $12.5 \mathrm{~m}^{2}$ of benthos per depth and site. We measured coral community composition and water quality of one site outside of Nikko Bay (N1) and six sites within Nikko Bay (N2-N7) at similar depths $(\sim 5 \mathrm{~m})$ showing different $\Omega_{\text {arag }}$ conditions (1.39-3.45) for the analyses.

Sites N1 to N5 were surveyed in November 2015 while sites N6 and N7 were surveyed in August 2014. No major disturbances within Nikko Bay (e.g. bleaching events) were observed between the two benthic survey dates. Benthic photographs were analyzed using CPCe software ${ }^{51}$. The benthic substrate directly below five random points per photograph was classified into benthic categories as described in several previous studies (e.g. Houk and van Woesik ${ }^{52}$, Golbuu et al. ${ }^{14}$, Gouezo et al. ${ }^{17}$, Houk et al. ${ }^{15}$ ). The benthic categories included live corals (to the genus level), fleshy macroalgae (identified to the genus level), turf algae, other invertebrates (e.g. sponges, ascidians, gorgonians), crustose coralline algae (CCA), and non-living substrates (e.g. bare rock, rubble, sand). 
The percentage cover of benthic categories at each site and depth was the result of the average of percentage cover among the five transects.

Transplantation experiment. Two nubbins of $5 \mathrm{~cm}$ length were collected by cutting pliers from each of 12 Porites cylindrica colonies in September 2015 from Nikko Bay (sites N5) and a reference site at Malakal Bay (site M1) at 2-3 m depths, respectively. The M1 site was selected as reference site because the coral community structure was similar to Nikko Bay and dominated by P. cylindrica, while seawater carbonate chemistry and seawater temperatures were close to the conditions found outside the bay such as at site N1. Sampled corals were put within a container with seawater bubbled with an air-pump, and transported by boat after sampling to the Palau International Coral Reef Center, arriving within $1 \mathrm{~h}$ (PICRC, Fig. 1b, c). After bringing all samples to the center, coral nubbins were each glued individually onto the top of plastic bolts using epoxy glue, and transplanted back to the same site from which they were collected. After one month, all nubbins were recovered and buoyant wet weights were measured with an electronic balance (0.1 mg precision HR-200, A\&D, Japan) twice for each nubbin. Thereafter, coral nubbins were reciprocally transplanted to the two sites, with each one nubbin of 12 colonies collected from the 2 sites transplanted to each 2 sites $(n=24$ per site). During transplantation, both seawater temperatures and light intensities were logged at $10 \mathrm{~min}$ intervals using temperature (CO-UA002, HOBO, Onset Corp.) and light sensor loggers (DEFI-L, JFE Advantech, cleaned every weak), respectively.

Eighteen days after transplantation, all nubbins were recovered and the buoyant wet weights of all nubbins were measured. Skeletal dry weights were calculated using aragonite density $\left(2.94 \mathrm{~g} \mathrm{~cm}^{-3}\right)$ according to Davis ${ }^{53}$, and calcification rates were calculated by the change of skeletal dry weights during transplantation and normalized by the surface areas measured using the aluminum foil technique ${ }^{54}$. Additionally, photosynthesis and respiration rates were measured for 9 out of 12 nubbins in each condition. Coral nubbins ( 36 nubbins in total) were first cleaned to remove any attached algae on the coral surface, and each nubbin was then placed individually in an airtight glass container (volume $=400 \mathrm{ml}$ ) filled with seawater collected from the same site where the corals were transplanted, placed under LED light $\left(250 \mu \mathrm{mol}\right.$ photon $\left.\mathrm{m}^{-2} \mathrm{~s}^{-1}\right)$ and photosynthesis was measured during daytime (11:00-14:00). One extra incubation container without a nubbin was also added as a control. Seawater within the container was continuously stirred with a magnetic stirrer $(450 \mathrm{rpm})$ during incubation and oxygen concentrations were measured at 0,20 and $40 \mathrm{~min}$ using an oxygen sensor (Fibox 3 , PreSens) calibrated with $100 \%$ saturated and $0 \%$ oxygen water prepared by $\mathrm{Na}_{2} \mathrm{SO}_{3}$. The same procedure was also conducted at night (20:00-22:00) under dark conditions to measure the respiration rate. Net photosynthesis ( $\mathrm{Pn}$ ) and respiration (R) rates were calculated by the following equation, where $\mathrm{V}$ is volume $(\mathrm{ml})$, $\mathrm{T}$ is time in hours, and SA is the surface area of the coral $\left(\mathrm{cm}^{-2}\right)$. Gross photosynthesis $(\mathrm{Pg})$ was calculated by Pn minus R.

$$
\text { Pn or } \mathrm{R}\left(\mu \mathrm{mol} \mathrm{O} \mathrm{cm}^{-2} \mathrm{~h}^{-1}\right)=\Delta\left[\mathrm{O}_{2}\right] *\left(\mathrm{~V}_{\text {chamber }}-\mathrm{V}_{\text {coral }}\right) / \mathrm{T} * \mathrm{SA}
$$

Seawater volume versus coral nubbin size was care to minimize the change in carbonate chemistry of the seawater within the container during the incubation due to the photosynthesis and respiration by the corals, and the seawater $\mathrm{pH}$ change was kept to be smaller than 0.08 , which gives in average $\mathrm{pCO}_{2}$ change of $200 \mu \mathrm{mol}$.

Zooplankton. Zooplankton were sampled at night after sunset for three days (11, 12 and 13 March 2016) from three sites (N5, N7, and M1) using a $100 \mathrm{~m}$ Nansen plankton net (30 cm diameter). Horizontal tows were conducted 5 times at 1-3 $\mathrm{m}$ depth per site, and the filtered volume was recorded with a flowmeter. Zooplankton samples were split and one-half of the sample was preserved in $5 \%$ borated-buffered formalin. Individual numbers of all zooplankton and copepods of the formalin fixed samples were counted under a microscope.

Statistical methods. Differences in seawater qualities inside and outside Nikko Bay were analyzed using Wilcoxon signed-rank test. Redundancy analysis (RDA) was conducted as a constrained ordination technique to relate the coral communities to seawater environmental variables. Input for the RDA consisted of coral coverage data that were first transformed using the decostand function in the R package vegan ${ }^{55}$. In the present case, the Hellinger distance was used. Generalized linear models (GLMs, family= quasipoisson) were used to evaluate the relation between $\Omega_{\text {arag }}$ and coral and other benthic coverage. The calcification rates of the transplantation experiment were evaluated with a Generalized Linear Mixed Effects model (family=Gamma) with origin site and transplanted site and its interaction as fixed effects and colony as random effect. Net photosynthesis, respiration (log transformed), and Pg:R (log transformed) of the transplantation experiment were evaluated with a linear mixed-effect model (REML) with origin site and transplanted site and its interaction as fixed effects and colony as random effect. Tukey's HSD test was conducted when there was a significant interaction. Differences of zooplankton and copepod abundances among sites were tested with student t-test. All statistical analyses were conducted using R (version 3.6.3) ${ }^{56}$.

Received: 19 January 2021; Accepted: 12 May 2021

Published online: 27 May 2021

\section{References}

1. Hoegh-Guldberg, O. et al. Coral reefs under rapid climate change and ocean acidification. Science 318, 1737-1742 (2007).

2. Pandolfi, J. M. et al. Projecting coral reef futures under global warming and ocean acidification. Science 333, 418-422 (2011).

3. Hughes, T. P. et al. Global warming and recurrent mass bleaching of coral. Nature 543, 373-377 (2017). 
4. Lough, J. M., Anderson, K. D. \& Hughes, T. P. Increasing thermal stress for tropical coral reefs: 1871-2017. Sci. Rep. 8, 6079, doi:https://doi.org/10.1038/s41598-018-24430-9

5. Fabricius, K. E., Mieog, J. C., Colin, P. L., Idip, D. \& Van Oppen, M. J. H. Identity and biodiversity of coral endosymbionts (zooxanthellae) from three Palauan reefs with contrasting bleaching, temperature and shading histories. Mol. Ecol. 13, 2445-2458 (2004).

6. Berkelmans, R. \& van Oppen, M. J. H. The role of zooxanthellae in the thermal tolerance of corals: a 'nugget of hope' for coral reefs in an era of climate change. Proc. R. Soc. B. 273, 2305-2312 (2006).

7. Silverstein, R. N., Cunning, R. \& Baker, A. C. Tenacious D: Symbiodinium in clade D remain in reef coral at both high and low temperature extremes despite impairment. J. Exp. Biol. 220, 1192-1196 (2017).

8. Kleypas, J. A. et al. Impacts of ocean acidification on coral reefs and other marine calcifiers: A guide for future research. 88 pp. Report of a workshop sponsored by NSF, NOAA and the U.S. Geological Survey. St. Petersburg, Florida (2006).

9. Orr, J. C. Anthropogenic ocean acidification over the twenty-first century and its impact on calcifying organisms. Nature 437, 681-686 (2005).

10. Pandolfi, J. M., Connolly, S. R., Marshall, D. J. \& Cohen, A. L. Projecting coral reef futures under global warming and ocean acidification. Science 333, 418-422 (2011).

11. van Woesik, R. et al. Climate-change refugia in the sheltered bays of Palau: analogous of future reefs. Ecol. Evol. 2, 2474-2484 (2012).

12. Golbuu, Y. et al. Long-term isolation and local adaptation in Palau's Nikko Bay help corals thrive in acidic waters. Coral Reefs 35, 909-918 (2016).

13. Shamberger, K. E. F. et al. Diverse coral communities in naturally acidified waters of a Western Pacific reef. Geophys. Res. Lett. 41, 499-504 (2014).

14. Golbuu, Y. et al. Palau's coral reefs show differential habitat recovery following the 1998-bleaching event. Coral Reefs 26, 319-332 (2007).

15. Houk, P. et al. Predicting coral-reef futures from El Nino and Pacific decadal oscillation events. Sci. Rep. 10, 7735 (2020).

16. Colin, P. L. Ocean warming and the reefs of Palau. Oceanog. 31, 126 (2018).

17. Gouezo, M. et al. Drivers of recovery and reassembly of coral reef communities. Proc. R. Soc. B 286, 20182908. https://doi.org/10. 1098/rspb.2018.2908 (2019).

18. Fabricius, K. E. et al. Losers and winners in coral reefs acclimatized to elevated carbon dioxide concentrations. Nature Clim. Change 1, 165-169 (2011).

19. Inoue, S., Kayanne, H., Yamamoto, S. \& Kurihara, H. Spatial community shift from hard to soft corals in acidified water. Nature Clim. Change 3, 683-687 (2013).

20. Enochs, I. C. et al. Shift from coral to macroalgae dominance on a volcanically acidified reef. Nature Clim. Change 5, 1083-1088 (2015).

21. Crook, E. D. et al. Calcifying coral abundance near low-pH springs: implications for future ocean acidification. Coral Reefs 31, 239-245 (2012).

22. Yates, K. K. et al. Diverse coral communities in mangrove habitats suggest a novel refuge from climate change. Biogeoscience 11, 4321-4337 (2014).

23. Barkley, H. C. et al. Changes in coral reef communities across a natural gradient in seawater pH. Science Adv. 1, e1500328 (2015).

24. Soliman, T., Fernandez-Silva, I., Kise, H., Kurihara, H. \& Reimer, J. D. Population differentiation across small distances in a coral reef-associated vermetid (Ceraesignum maximum) in Palau. Coral Reefs 38, 1159-1172 (2019).

25. Camp, E. F. et al. Reef-building corals thrive within hot-acidified and deoxygenated waters. Sci. Rep. 7, 2434 (2017).

26. Richards, Z. T., Garcia, R. A., Wallace, C. C., Rosser, N. L. \& Muir, P. R. A diverse assemblage of reef corals thriving in a dynamic intertidal reef setting (Bonaparte archipelago, Kimberley, Australia). PLoS ONE 10, e0117791 (2015).

27. Manzello, D. P. et al. Poorly cemented coral reefs on the eastern tropical Pacific possible insights into reef development in a high$\mathrm{CO}_{2}$ world. Proc. Natl. Acad. Sci. USA. 105, 10450-10455 (2008).

28. Camp, E. F. et al. The future of coral reefs subject to rapid climate change: Lessons from natural extreme environments. Front. Mar. Sci. 5, 4. https://doi.org/10.3389/frmars.2018.00004 (2018).

29. IPCC Climate Change 2013: The physical Science Basis. Working Group I Contributed to the Fifth Assessment Report the Intergovernmental Panel on Climate Change. Eds. Stocker T. F. et al. Cambridge University Press (2013).

30. Kayanne, $\mathrm{H}$. et al. Seasonal and bleaching-induced changes in coral reef metabolism and $\mathrm{CO}_{2}$ flux. Glob. Biogeochem. Cycles 19, GB3015, doi:https://doi.org/10.1029/2004GB002400 (2005).

31. DeCarlo, T. M. et al. Community production modulates coral reef $\mathrm{pH}$ and the sensitivity of ecosystem calcification to ocean acidification. J. Geophys. Res. Oceans 122, 745-761 (2017).

32. Silverman, J., Lazar, B., Cao, L., Caldeira, K. \& Erez, J. Coral reefs may start dissolving when atmospheric $\mathrm{CO}_{2}$ doubles. Geophys. Res. Lett. 36, L05606 (2009).

33. McGillis, W. R. et al. Direct covariance air-sea $\mathrm{CO}_{2}$ fluxes. J. Geophys. Res. 106, 16729-16745 (2001).

34. Hii, Y.-S., Bolong, A.M.A., Yang, T.-T. \& Liew, H.-C. Effect of elevated carbon dioxide on two scleractinian corals: Porites cylindrica (Dana, 1846) and Galaxea fascicularis (Linnaeus, 1767). J. Mar. Sci. 215196 (2009).

35. Suggett, D. J. et al. Light availability determines susceptibility of reef building corals to ocean acidification. Coral Reefs 32, 327-337 (2013).

36. Kavousi, J., Reimer, J. D., Tanaka, Y. \& Nakamura, T. Colony-specific investigations reveal highly variable responses among individual corals to ocean acidification and warming. Mar. Environ. Res. 109, 9-20 (2015).

37. McCulloch, M., Falter, J., Trotter, J. \& Montagna, P. Coral resilience to ocean acidification and global warming through $\mathrm{pH}$ upregulation. Nat. Clim. Change 2, 623-627 (2012).

38. Fantazzini, P. et al. Gains and losses of coral skeletal porosity changes with ocean acidification acclimation. Nat. Commun. 6, 7785. https://doi.org/10.1038/ncomms8785 (2015).

39. Mollica, N. R. et al. Ocean acidification affects coral growth by reducing skeleton density. Proc. Natl. Acad. Sci. USA 115, 1754-1759 (2018).

40. Hourbrèque, F. \& Ferrier-Pagès, C. Heterotrophy in tropical scleractinian corals. Biol. Rev. 84, 1-17 (2009).

41. Edmunds, P. J. Zooplanktivory ameliorates the effects of ocean acidification on the reef coral Porites spp. Limnol. Oceanogr. 56, 2402-2410 (2011).

42. Kurihara, H., Suhara, Y., Mimura, I. \& Golbuu, Y. Potential acclimatization and adaptative responses of adult and trans-generational coral larvae from naturally acidified habitat. Front. Mar. Sci. 7, 581160 (2020).

43. LaJeunesse, T. C. et al. Systematic revision of Symbiodiniaceae highlights the antiquity and diversity of coral endosymbionts. Curr. Biol. 28, 1-11 (2018).

44. Oliver, T. A. \& Palumbi, S. R. Do fluctuating temperature environments elevate coral thermal tolerance?. Coral Reefs 30, 429-440 (2011).

45. Lewis, E. \& Wallace, D. CO2SYS: program developed for the $\mathrm{CO}_{2}$ system calculations. Carbon Dioxide Inf. Anal. Center. Oak Ridge National Laboratory, US Department of Energy, Oak Ridge, TN, USA (1998).

46. Mehrbach, C., Culberson, C. H., Hawley, J. E. \& Pytkowicz, R. M. Measurement of the apparent dissociation constant of carbonic acid in seawater at atmospheric pressure. Limnol. Oceanog. 18, 897-907 (1973). 
47. Dickson, A.G. \& Millero, F.J. A comparison of the equilibrium constants for the dissociation of carbonic acid in seawater media. Deep Sea Res. Part A. Oceanogr. Res. Pap. 34, 1733-1743 (1987).

48. Mucci, A. The solubility of calcite and aragonite in seawater at various salinities, temperatures, and one atmosphere total pressure. Am. J. Sci. 183, 780-799 (1983).

49. Anderson, L.G. et al. Determination of total alkalinity and total dissolved inorganic carbon. P. 127. In Grasshoff. K., Kremling, K., \& Ehrhardt, M. (eds.). Methods of seawater analysis. Wiley-WCH (1999).

50. Watanabe, A. et al. Analysis of the seawater $\mathrm{CO}_{2}$ system in the barrier reef-lagoon system of Palau using total alkalinity-dissolved inorganic carbon diagrams. Limnol. Oceanogr. 51(4), 1614-1628 (2006).

51. Kohler, K. E. \& Gill, S. M. Coral point count with Excel extensions (CPCe): A visual basic program for the determination of coral and substrate coverage using random point count methodology. Comput. Geosci. 32, 1259-1269 (2006).

52. Houk, P. \& van Woesik, R. Coral reef benthic video surveys facilitate long-term monitoring in the Commonwealth of the Northern Mariana Islands: toward an optimal sampling strategy. Pac. Sci. 60, 175-187 (2006).

53. Davis, P. S. Short-term growth measurements of coral using an accurate buoyant weighing technique. Mar. Bio. 101, 389-395 (1989).

54. Marsh, J. A. Primary productivity of reef-building calcareous red algae. Ecology 51, 255-263 (1970).

55. Oksanen, J. et al. VEGAN: community Ecology Package-R package version 2.4-3. https://CRAN.R-project.org/package= vegan (2017).

56. R Core Team. R: A Language and Environmental for Statistical Computing. R Foundation for Statistical Computing. https:// www.r-project.org R version 3.6.3 (2020).

\section{Acknowledgements}

We are grateful to Asap Bukurrou, Arius Merep, Seiji Nakaya, Geraldine Rengiil, Randa Jonathan, Geory Mereb, Jay Oruetamor, Piera Biondi, Giovanni Masucci and all staff of the Palau International Coral Reef Center for their support and assistance during this work. This work was supported by funding from the Japan International Cooperation Agency (JICA)-Japan Science and Technology (JST) SATREPS program, and the Japan Society for the Promotion of Science (JSPS) KAKENHI Grant Numbers 16H05772 and 20H05790.

\section{Author contributions}

H.K. led the research planning study design, all authors contributed to data collection, H.K., A.W., A.T. and T.K. conducted data analyses, H.K. produced figures, H.K led the writing of the manuscript and all authors contributed to the final manuscript preparation.

\section{Competing interests}

The authors declare no competing interests.

\section{Additional information}

Supplementary Information The online version contains supplementary material available at https://doi.org/ 10.1038/s41598-021-90614-8.

Correspondence and requests for materials should be addressed to H.K.

Reprints and permissions information is available at www.nature.com/reprints.

Publisher's note Springer Nature remains neutral with regard to jurisdictional claims in published maps and institutional affiliations.

(c) (i) Open Access This article is licensed under a Creative Commons Attribution 4.0 International License, which permits use, sharing, adaptation, distribution and reproduction in any medium or format, as long as you give appropriate credit to the original author(s) and the source, provide a link to the Creative Commons licence, and indicate if changes were made. The images or other third party material in this article are included in the article's Creative Commons licence, unless indicated otherwise in a credit line to the material. If material is not included in the article's Creative Commons licence and your intended use is not permitted by statutory regulation or exceeds the permitted use, you will need to obtain permission directly from the copyright holder. To view a copy of this licence, visit http://creativecommons.org/licenses/by/4.0/.

(c) The Author(s) 2021, corrected publication 2021 